\title{
Application of the Sectional Method to Investigate Particle Number and Soot Mass in Ethanol and Gasoline Fueled Premixed Spark Ignition Engines
}

\author{
Valentina Pessina ${ }^{1 *}$, Marco Del Pecchia ${ }^{1}$, Sebastiano Breda $^{2}$, Luca Dalseno ${ }^{2}$, Massimo \\ Borghi $^{1}$ \\ ${ }^{1}$ Department of Engineering "Enzo Ferrari”, University of Modena and Reggio Emilia, Via Vivarelli \\ 10, Modena 41125, Italy \\ ${ }^{2}$ R\&D CFD S.R.L., Via Tacito 59, Modena 41123, Italy
}

\begin{abstract}
Emission modelling is still a timely topic in the engine research community. Soot emission reduction has gained its spotlight among the pollutants-related issues mainly due to the renewed interest in Gasoline Direct Injection. The conjunction of experimental measurements and numerical investigations provides an effective tool to cope with the constant evolution of the emission regulations. Thus, numerical models must be validated over a wide range of engine operating points and fuels. To this aim, the Sectional Method was applied to investigate Particulate Matter and Particle Number produced during combustion in a premixed spark ignition engine using 3D-CFD. Soot-related quantities were investigated for different values of equivalence ratio (from 1.0 up to 1.5) as well as for different fuels. Three different fuel types were examined: a commercial nonoxygenated American gasoline (TIER-2), a commercial Chinese gasoline (CHINA-6) with ethanol $10 \% \mathrm{vol}$ and pure Ethanol (E100). A detailed chemistry-based tabulated approach was exploited to compute a dedicated soot library, for each of the analyzed fuels, by means of $0 \mathrm{D}$ chemical kinetic simulations using a constant pressure reactor approach. Numerical results were compared to a database of experimental measurements collected from literature. The sooting tendency threshold dependency on equivalence ratio was also investigated and the results showed that the ethanol is the less sooting among the examined fuels, while the non-oxygenated gasoline exhibited the highest soot mass and Particle Number. This paper provides a CFD-based benchmark for soot mass and Particle Number for three fuel types with largely different chemical nature.
\end{abstract}

\section{Introduction}

Nowadays, the growth in the energy consumption and the progressive tightening of the emission regulations are two facets of energy generation. International agreements strategically address climate change threat by proposing both short and long term solutions

\footnotetext{
${ }^{*}$ Corresponding author: valentina.pessina@unimore.it
} 
to tackle the emissions reduction in the next years up to 2050. The low-carbon emission targets, as well as the $\mathrm{NO}_{\mathrm{x}}$ and the regulations for Particulate Mass (PM), require the joint effort of the scientific community in order to find alternative and sustainable solutions to differentiate the energy sources and to control the overall pollutant emissions. As for the transportation field, the energy demand is increasing at a fast pace, while the alternative technologies, such as BEVs (Battery Electric Vehicles) or FCVs (Fuel-Cell Vehicles), need to be further developed in order to be considered as viable and sustainable alternatives. When compared to the conventional propulsion systems, the alternative solutions should be considered advantageous, in terms of emissions, only if the comparison is made on a wholecycle-life basis, and not just on the mere performance on the road. As reported by [1-2-3-4] petroleum-derived liquid fuels provide the source of energy for more than the $90 \%$ of the road transportation nowadays. Since transportation field is the backbone of the global economy, the improvement of internal combustion engines (ICEs) is still a key research topic, along with those alternative propulsion solutions, such as the hybrid propulsion systems. Among the coping strategies to reduce the emissions of the transportation sector, the use of alternative fuels provides a worthwhile solution. For this reason, the optimization of the unconventional fuels (e.g. biofuels, and low-carbon fuels, such as methane or syngas) combustion process is essential. In this scenario, experimental measurements provide useful data to Multidimensional Computational Fluid Dynamics (3D-CFD) simulations to calibrate and improve the accuracy of numerical models. Recently, several studies attempted to validate numerical models, against experimental data, for the combustion of less sooting fuels, such as butanol [5-6] and pure syngas in optically-accessible research engines [7]. Moreover, 3D-CFD is a valuable tool for investigating the knock tendency in SI engines [89-10], which is a key facet when the downsizing of an engine is taken into account. Since charge stratification influences the pollutant formation process, numerical investigation can be successfully applied to spray simulations for both traditional [11-12] and unconventional applications, such as methanol and water injection [13-14-15] that can lower the in-cylinder temperature, thus influencing the overall combustion process. Efforts in exploring 3D-CFD potential, for gaining further insight in the combustion process efficiency of alternative fuels, are essential to achieve a reasonable accuracy, when modelling the combustion processes. In particular, with the current and future strict regulations on the emissions, 3D-CFD emission models can provide a helpful insight at a reduced cost. However, these models must be validated to ensure reliability. In this framework, the Sectional Method [16-17-18] is among the most advanced soot emission models and it has been applied with promising results to compression-ignition engines [19-20-21], but the renewed interest in Direct-Injection SparkIgnition (DISI) engines promoted the pivoting of the Sectional Method towards Gasoline Direct Injection (GDI) applications [22-23-24-25-26]. The GDI engine-out emissions are bounded by very strict soot regulations, thus limiting the Particulate Mass (PM) and the Particle Number (PN) is essential. For this reason, concern over soot emissions is no more a Diesel engine prerogative and the 3D-CFD models dealing with soot formation are required to be suitable also for GDI applications. The Sectional Method has been adapted to DirectInjection Spark-Ignition engines and an example of its application to GDI engine fueled with the a representative European gasoline was reported by [25-26]: the particle size distribution was compared to an experimental dataset derived from a single-cylinder research engine equipped with an optical access. While constituting a solid investigation tool, the Sectional Method model prediction is inevitably affected by the degree of accuracy to which the 3DCFD model is able to predict mixture stratification at spark-timing in GDI units, which is a key parameter influencing the sooting tendency as reported in [27]. In this scenario, the experimental measurements carried out by Hageman et al. [28] on a fully-premixed SI (Spark-Ignition) engine provides a "mixture stratification uncertainty-free" dataset to investigate the ability of the Sectional Method to predict the critical sooting tendency 
equivalence ratio value for a variety of fuel types. In this study, to assess the Sectional Method reliability, when applied to SI combustion simulations, three fuel types were tested: a non-oxygenated commercial gasoline (TIER-2 [29]), an oxygenated commercial gasoline (CHINA-6 [29] with ethanol $10 \% \mathrm{vol}$ ), and pure ethanol. 3D-CFD simulations were carried out exploiting a simplified engine-like geometry, replicating as accurately as possible the experimental conditions from [28], which provided the experimental soot measurements used for the validation of the 3D-CFD simulations. For each fuel type, the premixed combustion process was simulated over six different values of equivalence ratio $(\phi)$, ranging from 1.0 to 1.5 as in [28], to spot the critical threshold $\phi$ values whereby the onset of a pronounced numerical sooting tendency was observed and compared with the same results from experiments for a commercial non-oxygenated gasoline.

\section{Methodology}

\subsection{Sectional Method Overview}

In this study, the Sectional Method was applied to provide information on soot-related quantities, such as: Particulate Mass (PM), Particle Number (PN), and Particle Size Distribution Function (PSDF). As extensively discussed by [21-24-25-26], the Sectional Method is a 3D-CFD model that predicts the PN, PM, and PSDF of soot particles generated by the combustion process. To account for the soot particle different sizes, this model relies on a volume-based discretization of the particle population constituting the PSDF. The PSDF is discretized by dividing the PSDF itself into a finite number of sections. Each section is populated by particles characterized by an equal representative mean volume $\mathrm{v}_{\mathrm{i}, \mathrm{m}}$, calculated as the arithmetic average of the lower and upper boundaries of the generic $\mathrm{i}^{\text {th }}$ section, identified as in Eq. 1(a)-(b).

$$
v_{i, \min }=1.5 \cdot v_{P A H} \cdot 2^{i-1} \quad \text { (1 a) } \quad v_{i, \max }=2 \cdot v_{i, \min }
$$

The minimum volume throughout all the sections belongs to the smallest particles resulting from the nucleation due to the collision of two soot precursors in the gaseous phase, commonly named PAHs (Polycyclic Aromatic Hydrocarbons). This mathematical description of the soot formation accounts for all the main phenomena involved in soot formation: physics-based phenomena, such as nucleation, condensation, and coagulation, as well as the chemistry-based mechanisms that increase (surface growth) or decrease (oxidation) the size of the soot particles. When drawing up the Sectional Method, the first assumption sets the shape of the soot particle as spherical and the soot particles are considered to have an homogeneously distributed mass, assuming a fixed density value $\rho_{\text {soot }}$ for the entire particles population. However, as the experimental measurements suggest, soot particle density decreases as the dimension of the soot particle increases [30] and this assumption could lead to particle mass overestimation. As extensively reported by [21-2425-26], for each of the finite number of sections, a transport equation, reported is Eq. 2, is solved to compute the soot mass fraction $\widetilde{Y}_{\text {soot,i }}$ in the $i^{\text {th }}$ section, which is related to the $Q_{i}$ by the relation shown in Eq. 3 , where $\bar{\rho}$ is the gas-phase density, $\rho_{\text {soot }}$ is the soot density, and $\mathrm{D}_{\text {soot,t }}$ is the turbulent diffusion coefficient.

$$
\frac{\partial \bar{\rho} \widetilde{Y}_{\text {soot }, i}}{\partial t}+\nabla \cdot\left(\bar{\rho} \tilde{u} \widetilde{Y}_{\text {soot }, i}\right)=\nabla \cdot\left(\bar{\rho} D_{\text {soot }, t} \nabla \bar{\rho} \widetilde{Y}_{\text {soot }, i}\right)+\rho_{\text {soot }} . \text { (2) } Q_{i}=\frac{\bar{\rho}}{\rho_{\text {soot }}} \cdot \tilde{Y}_{\text {soot }, i}
$$

In the transport equation, the source term $\widetilde{\Omega}_{\text {soot }, i}$ is a key factor of this model. This source term is expressed as shown in Eq. 4 and it accounts for all of the soot formation mechanisms: 
particle inception $\left(\widetilde{\Omega}_{P I, i}\right)$, condensation $\left(\widetilde{\Omega}_{C O N D, i}\right)$, coagulation $\left(\widetilde{\Omega}_{C O A G, i}\right)$, oxidation $\left(\widetilde{\Omega}_{O X i}\right)$, and surface growth $\left(\widetilde{\Omega}_{S G, i}\right)$.

$$
\tilde{\Omega}_{s o o t, i}=\tilde{\Omega}_{P I, i}+\tilde{\Omega}_{C O N D, i}+\tilde{\Omega}_{C O A G, i}+\tilde{\Omega}_{O X i}+\tilde{\Omega}_{S G, i} \quad \text { with }\left.\tilde{\Omega}_{P I, i}\right|_{i \neq 1}=0
$$

To provide a closure to the Sectional Method equations, five coefficients have to be assigned in each cell of the fluid domain depending on the thermodynamic conditions $\left(\mathrm{p}^{*}, \mathrm{~T}^{*} \mathrm{u}\right)$, on the local mixture properties, thus the equivalence ratio $\phi^{*}$ and $\mathrm{EGR}^{*}$, and on the progress variable $c^{*}$. The meaning of the aforementioned coefficients and their relationship with the source terms in Eq. 4 are summarized in Table 1.

Table 1. Influence of the chemistry-based coefficients and the soot source terms implemented in the Sectional Method.

\begin{tabular}{|c|c|c|}
\hline Coefficient & Description & Source term \\
\hline$\widehat{\mathrm{RPAH}}$ & Rate of formation of the soot precursors in the gaseous phase & $\widetilde{\Omega}_{C O N D, i}$ \\
\hline$\tilde{\mathrm{k}}_{\mathrm{d}}$ and $\tilde{\mathrm{k}}_{\mathrm{rev}}$ & $\begin{array}{l}\text { Influence on the surface growth of the particles (forward and } \\
\text { backward reaction rate constants in the HACARC mechanism } \\
\qquad 25] \text { ) }\end{array}$ & $\widetilde{\Omega}_{S G, i}$ \\
\hline$\tilde{\mathrm{k}}_{\mathrm{O}_{2}}$ and $\tilde{\mathrm{k}}_{\mathrm{OH}}$ & Influence on the oxidation in the HACARC mechanism [25] & $\widetilde{\Omega}_{O X i}$ \\
\hline
\end{tabular}

It is worth to highlight that the source term related to the coagulation $\widetilde{\Omega}_{C O A G, i}$ is independent of chemistry, since the coagulation is merely driven by the collision between particles. In this study, the chemistry-dependent coefficients were obtained from dedicated chemical kinetic $0 \mathrm{D}$ simulations as discussed in the next section. With regards to the Sectional Method implemented in STAR CD v4.30 [31], it is important to clarify the nature of the interplay between the soot chemistry and the turbulent combustion model adopted, which is EFCM$3 Z$ [31]. The soot model and the combustion model are decoupled since the soot-chemistry timescale is assumed to be longer than the characteristic turbulence timescale, hence the Damköhler Number related to soot $\left(\mathrm{Da}_{\text {soot }}=\tau_{\text {turb }} / \tau_{\text {soot-chemistry }}<1\right)$ is much smaller

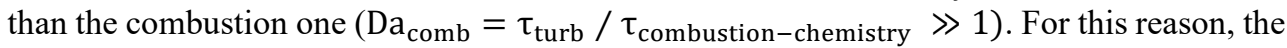
soot modelling is passive, thus it has no impact on the combustion model.

\subsection{Fuel Types and Soot Constant Pressure Libraries}

As previously highlighted, the source term $\widetilde{\Omega}_{\text {soot }, i}$ has a key role in soot formation modelling and it is expressed by a summation of the individual sources for the different soot formation mechanisms as reported in Eq.4. In the implemented version of the Sectional Method [18-20], all the source terms, but the one related to coagulation, are influenced by the five coefficients reported in Table 1 , and these coefficients account for the chemistrybased processes contribution to $\widetilde{\Omega}_{P I, i}, \widetilde{\Omega}_{C O N D, i}, \widetilde{\Omega}_{O X}$, and $\widetilde{\Omega}_{S G, i}[18,20]$. Therefore, it is essential to accurately estimate these values at engine-relevant conditions. In this study, a 0D chemical kinetic simulation approach has been exploited to estimate the coefficients in Table 1 , at the thermodynamic and mixture quality conditions relevant for the analyzed engine case and accounting for the fuel composition. These coefficients are stored in dedicated libraries for each of the fuels under study, thus exploiting the typical advantages of the tabulated approach. To this purpose, the fuel composition must be provided as an input. For pure ethanol simulation, a single component can be easily defined, while for TIER-2 and CHINA6 the definition of an appropriate fuel surrogate is a challenging task. Moreover, the chemical kinetic simulations rely on chemical reaction schemes, and the gasoline components should be all available in the selected reaction mechanism. A reasonable and effective solution is to formulate a surrogate fuel able to replicate most of the combustion-relevant properties, such 
as $\mathrm{H} / \mathrm{C}$ ratio (thus the stoichiometric air-to-fuel ratio), laminar flame speed, and RON. As shown in the methodology proposed by Del Pecchia et al. [25-32-33], the surrogate composition can be obtained by solving an overdetermined linear system of equations. In addition to the target properties, the Threshold Soot Index (TSI) was matched as well as extensively discussed by [25]. To match $\mathrm{H} / \mathrm{C}$ ratio, $\mathrm{O} / \mathrm{C}$ ratio, $\mathrm{RON}$, and $\mathrm{TSI}$, the overdetermined system of equations was solved using a lest-squares minimization approach. The composition of TIER-2 and CHINA-6 final surrogates derived by [25] are reported in Table 2 along with the main information of the gasoline tested in the experimental analysis reported by [28], labeled as EEE, just for the sake of providing a comparison between these gasolines.

Table 2. Properties of the fuel surrogates, of the ethanol, and of the EEE reported by Hageman [28]. The symbol [*] indicates the surrogate of the reference fuel.

\begin{tabular}{ccccccccc}
\hline & \multicolumn{10}{c}{ Properties } \\
\cline { 2 - 9 } Fuel/Surrogate & $\begin{array}{c}\text { H/C } \\
{[-]}\end{array}$ & $\begin{array}{c}\text { O/C } \\
{[-]}\end{array}$ & $\begin{array}{c}\text { AFRst } \\
{[-]}\end{array}$ & $\begin{array}{c}\text { RON } \\
{[-]}\end{array}$ & $\begin{array}{c}\text { MON } \\
{[-]}\end{array}$ & $\begin{array}{c}\text { TSI } \\
{[-]}\end{array}$ & $\begin{array}{c}\text { Aromatics } \\
{[\% \text { \%ol] }}\end{array}$ & $\begin{array}{c}\text { Oxygenates } \\
{[\% \text { \%ol] }}\end{array}$ \\
\hline TIER-2 [*][25] & 1.855 & 0.000 & 14.52 & 96.56 & 90.21 & 20.59 & 30 & 0 \\
\hline CHINA-6 [*][25] & 1.816 & 0.032 & 13.79 & 96.60 & 86.46 & 15.53 & 35 & 10 \\
\hline EEE [28] & 1.840 & 0.000 & - & 96.60 & 88.50 & - & 28 & 0 \\
\hline Pure Ethanol & 3.000 & 0.500 & 8.97 & 108.00 & 90.00 & - & 0 & 100 \\
\hline
\end{tabular}

As reported in Table 2, CHINA-6 surrogate has a higher aromatic content, but it is also the only surrogate containing ethanol $10 \% \mathrm{vol}$ and the presence of oxygenated compounds results in a reduction of soot emissions. This observation explains why CHINA-6 TSI is lower than the TIER-2 one, despite the higher aromatic content. Each reference fuel surrogate provides a simplified composition that replicates the main target properties of the reference fuel, which otherwise would be computationally unfeasible to exploit as input for the chemical kinetic simulations. To be more specific, the surrogate composition reported in $\%$ mol by [25] are: for CHINA-6 $14.36 \%$ n-heptane, $34.92 \%$ iso-octane, $40.38 \%$ toluene, and $10.34 \%$ ethanol, while TIER-2 contains $10.71 \%$ n-heptane, $55.12 \%$ iso-octane, $34.17 \%$ toluene and no ethanol is present. These compositions were used in this study to carry out chemical kinetic simulations for the commercial gasolines under study, while pure ethanol was accounted for as ethanol $100 \%$ vol. By using DARS v4.30 chemistry solver licensed by Siemens Digital Industries Software, the premixed combustion was simulated in 0D Constant Pressure (CP) reactors at engine-relevant conditions by using the reaction mechanism proposed by [34]. As a further remark, the output of each of the three simulations, one for each fuel, is a table in which values for the five coefficients $\widehat{\mathrm{RPAH}}, \tilde{\mathrm{k}}_{\mathrm{d}}, \tilde{\mathrm{k}}_{\mathrm{rev}}, \tilde{\mathrm{k}}_{\mathrm{O}_{2}}$, and $\tilde{\mathrm{k}}_{\mathrm{OH}}$ are stored as a function of $\left(\mathrm{p}^{*}, \mathrm{~T}^{*}{ }_{\mathrm{u}}, \phi^{*}, \mathrm{EGR}^{*}, \mathrm{c}^{*}\right)$. Such coefficients are recalled during runtime at a cell-wise level to solve Eq. 3. The adoption of a tabulated approach is advantageous, as it allows to account for the different chemical nature of the fuels while retaining low computational cost. As reported in [27], soot formation in flames is strongly affected by the chemical nature of the fuel. In Table 3, the validity range of the soot constantpressure libraries are reported, for the sake of completeness.

Table 3. Range of validity of the soot libraries where the $\overparen{\mathrm{RPAH}}, \widetilde{\mathrm{k}}_{\mathrm{d}}, \widetilde{\mathrm{k}}_{\mathrm{rev}}, \tilde{\mathrm{k}}_{\mathrm{O}_{2}}$, and $\widetilde{\mathrm{k}}_{\mathrm{OH}}$ are reported at engine like conditions.

\begin{tabular}{ccccc}
\hline $\begin{array}{c}\text { Unburnt } \\
\text { Temperature } \\
{[\mathbf{K}]}\end{array}$ & $\begin{array}{c}\text { Pressure } \\
{[\mathbf{b a r}]}\end{array}$ & $\begin{array}{c}\text { Equivalence } \\
\text { Ratio } \mathbf{\Phi} \\
{[-]}\end{array}$ & $\begin{array}{c}\text { EGR } \\
{[\%]}\end{array}$ & $\begin{array}{c}\text { Progress } \\
\text { Variable } \\
{[-]}\end{array}$ \\
\hline $500 \div 1000$ & $0.5 \div 44$ & $0.4 \div 2.5$ & $0 \div 20$ & $0.1 \div 1.0$ \\
\hline $500: 50: 1000$ & $\begin{array}{l}0.5,2,5,8,12,16,20, \\
24,28,32,36,40,44\end{array}$ & $0.4: 0.05: 2.0$ & $0: 5: 20$ & $0.1: 0.01: 1.0$ \\
\hline
\end{tabular}




\subsection{Engine Simulation Setup}

As previously mentioned, a simple engine geometry, as shown in Fig. 1a, was exploited in the present study to numerically investigate the experimental conditions investigated in [28]. A wireframe detail of the mesh is shown in Fig. 1b: the maximum number of cells is 32309 at BDC, the minimum is 20448 at BDC.

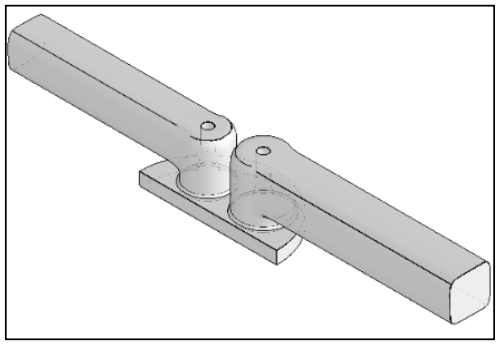

Fig. 1(a). Geometry of the 3D-CFD simple engine model at TDC.

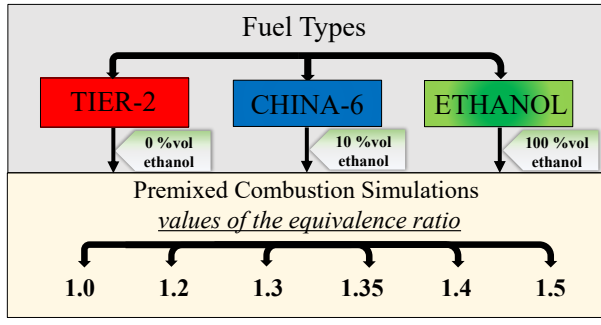

Fig. 2. Simulation case summary. The percentages represent the ethanol \%vol present in the fuel.

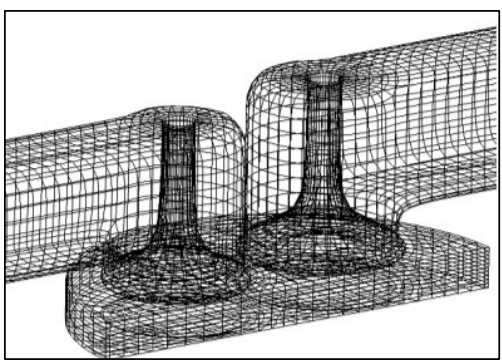

Fig. 1(b). Mesh grid detail of the 3D-CFD simple engine model at TDC.

\begin{tabular}{ccc}
\hline Engine Feature & $\begin{array}{c}\text { 3D-CFD } \\
\text { Model }\end{array}$ & $\begin{array}{c}\text { Experimental } \\
\text { Engine [28] }\end{array}$ \\
\hline $\begin{array}{c}\text { Compressio } \\
\text { n Ratio [-] }\end{array}$ & $12: 1$ & $11.97: 1$ \\
\hline Bore [mm] & 96 & 85.96 \\
\hline $\begin{array}{c}\text { Revving } \\
\text { speed [RPM] }\end{array}$ & 2100 & 2100 \\
\hline
\end{tabular}

Table 4. Engine features of the 3D-CFD model and of the experimental PFI engine used by Hageman [28].

The main features of the 3D-CFD engine model are reported along with those of the engine used by [28] in Table 4, in order to provide a little context. As for the turbulence treatment, a RANS approach was adopted by using the k- $\varepsilon$ RNG model and the High Reynolds Wall Treatment was adopted in conjunction with the GruMo Heat Transfer Model [35-36-37-3839-40]. The combustion modelling was undertaken by using the ECFM-3Z combustion model for SI applications [31]. As previously outlined, the Sectional Method was selected and the total number of sections was set to 30 , in order to model soot particles ranging from $1.18 \mathrm{~nm}$ to $961 \mathrm{~nm}$. This modelling choice allows to numerically cover the particle size range sampled in the reference experimental dataset provided in [28]. To test the solidity of the chosen numerical approach for soot modelling, no case-by-case tuning on the Sectional Model was allowed in this study. The engine cycle, thus the premixed combustion, was simulated for different values of equivalence ratio to spot the sooting threshold value of the equivalence ratio and the set of simulations was repeated for each of the three investigated fuels. Sooting threshold is defined as the value of the equivalence ratio above which soot formation due to the combustion becomes relevant. Since [28] provided a set of experimental data for a spark-ignition premixed engine fueled with gasoline, and another set of measurement with ethanol, a comparison between the experimental measurements and this study numerical results was possible. In particular, as reported by [28] the onset of a relevant production of soot can be observed for values of the equivalence ratio ranging from 1.3 to 1.35 , for a non-oxygenated commercial gasoline. As reported in [27], the sooting tendency is strongly influenced by the thermodynamic history of the combustion process. For this reason, particular care was devoted to the calibration of the combustion model, so that $50 \%$ 
of mass fuel burnt fell at the same crank angle position as in the experiments. Such choice ensures that a similar thermodynamic history over the engine cycle is retained. Moreover, to discard influence of initial conditions, three cycles were carried out for each case setup. To better portray the simulation cases that were carried out in this study, a summary is reported in Fig. 2. Three fuel types were tested in a premixed SI simple engine 3D-CFD model, and for each fuel, different values of equivalence ratio were considered to shed light on the sooting threshold value of the equivalence ratio.

\section{Results and discussion}

This study aims to spot the critical $\Phi$ sooting threshold value for the premixed combustion of three different fuels. Other soot-related quantities have been collected as well during the post-processing of the $3 \mathrm{D}-\mathrm{CFD}$ simulations. This study results show that the critical $\Phi$ sooting threshold value of the equivalence ratio can be spotted between 1.35 and 1.4, for an oxygenated commercial gasoline (CHINA-6), while for the non-oxygenated gasoline (TIER2 ) it is between 1.3 and 1.35 , this last is very similar to the threshold observed for ethanol 0 \%vol EEE experimentally investigated by [28]. Moreover, the different chemical nature of the investigated fuels gives different soot production patterns. Since the experimental study [28] reported soot particles ranging from $10 \mathrm{~nm}, 3 \mathrm{D}-\mathrm{CFD}$ results are analyzed considering a set of particles with a minimum mean diameter of $10 \mathrm{~nm}$, thus applying the same logic.

\subsection{Particle Number and Particulate Mass}

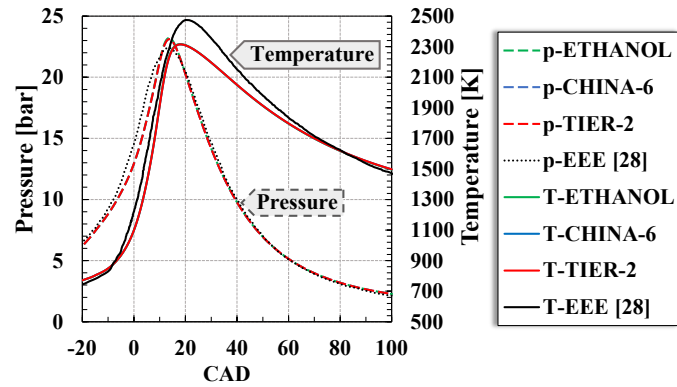

Fig. 3. Pressure and temperature: comparison of the 3D-CFD cases and the experimental data. Example provided for $\Phi=1.3$.

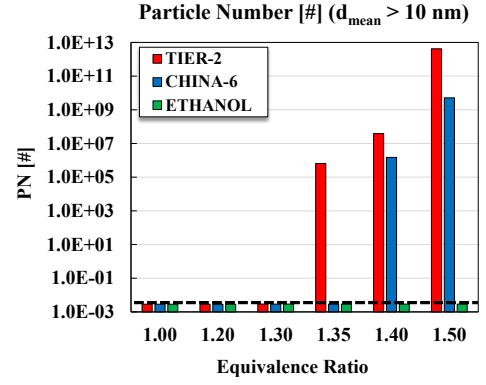

Fig. 4. 3D-CFD PN [\#] for TIER-2, CHINA-6, and pure ETHANOL for different equivalence ratio values.

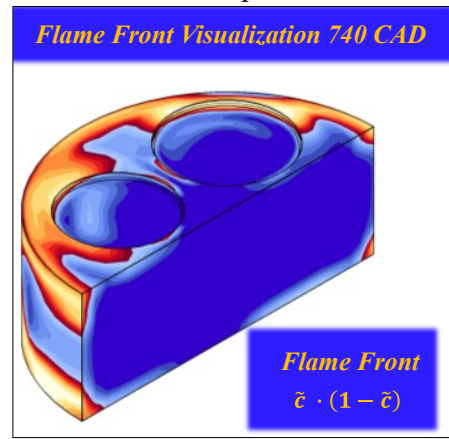

Fig. 5 (a) Flame Front: it is representative of both the examined gasolines for $\Phi=1.5$ case.

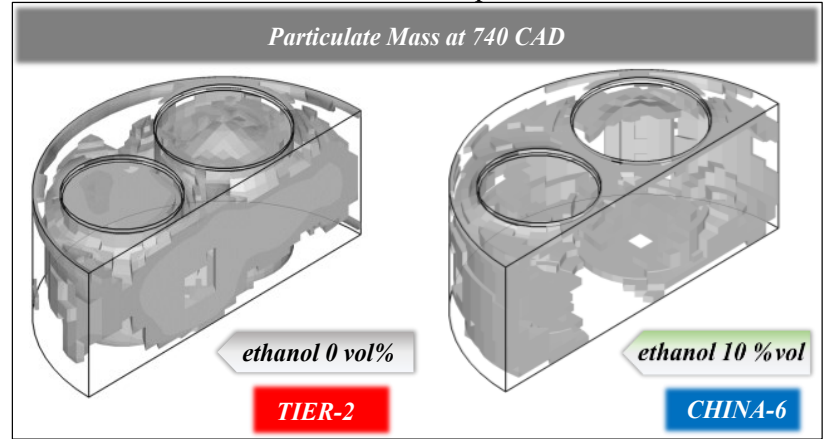

Fig. 5 (b) Cell-wise value of soot mass for the two examined types of gasoline for $\Phi=1.5$ case. 
As previously reported in the methodology section, the premixed combustion simulations were carried out on equal 50\% Mass Fraction Burnt phasing (MFB50) to ensure that the simulated cases had a similar combustion history to the experimental one. As visible in Fig. 3 , the calculated pressures (dashed line) and temperatures (solid line) are in good agreement with experimental data by [28]. Thanks to the dedicated tabulated approach, it is possible to account for the different fuel compositional effects on soot formation. Botero et al. [41] reported that the aromatics are the most sooting among the hydrocarbon classes, while the oxygenated compounds can significantly reduce soot production. As reported in Table 2, the aromatic content of TIER-2 surrogate and EEE [28] is comparable, while CHINA-6 surrogate is characterized by a higher aromatic content, counterbalanced by the presence of ethanol 10 $\%$ vol. Consequently CHINA-6 exhibits a lower soot production tendency than TIER-2. As for the numerical results, TIER-2 and CHINA-6 are compared in terms of soot production. As shown in Fig. 4, the number of particles is higher for TIER-2 than the CHINA-6 and this gap widens for equivalence ratio values higher than 1.35. The strong influence of ethanol content on soot formation is further confirmed by pure ethanol simulations, that exhibits a negligible soot production as shown in Fig.4. The influence of $\Phi$ variation is reported as well in Fig.4. Interestingly, in agreement with the experimental findings for a non-oxygenated gasoline, once the $1.3 \div 1.35$ value is overcome, the soot production becomes relevant in $3 \mathrm{D}$ CFD for the gasoline surrogates considered. The reduced sooting tendency shown by CHINA-6, is reinforced by considering the Particulate Mass (PM). For the sake of clarity, the flame front at $20 \mathrm{CAD}$ aTDC is plotted in Fig 5a by using the combustion progress variable $\tilde{c}$ [31] to visualize the combustion evolution inside the cylinder. In Fig.5b, a comparison of the soot mass in the fluid domain at the same crank angle position is reported for TIER-2 and CHINA-6 surrogates. As shown by the cell-wise soot mass plots in Fig. 5b, the soot mass produced by TIER-2 is found higher than the soot mass produced by CHINA6. 3D-CFD results clearly confirm the impact of the fuel chemical nature on the soot production. Interestingly, 3D-CFD confirms that the higher aromatic content in CHINA-6 is effectively counterbalanced by the presence of oxygenated compounds, so that CHINA-6 gasoline surrogate exhibits a lower sooting tendency than TIER-2 gasoline surrogate, in agreement with the experimental results obtained for the corresponding real fuels in [28].

\subsection{Particle Size Distribution Function}

The PSDF comparison is carried out by considering the integral of the PSDF from both 3D-CFD simulations and experimental measurements [28]. Since it is a function of equivalence ratio, the PSDF integral provides an immediate outlook on the sooting threshold of a given fuel. It is crucial to highlight that numerical results can only account for the soot produced by combustion of the fuel/air mixture, while experimental measurements [28-42] had shown a relevant contribution to soot formation deriving from engine-wear (metallicbased particles) and engine lubricant oil. Such non-fuel derived soot, named background soot (BGS), is accounted for by adding the value obtained integrating the PSDF curve relating to the EEE premixed combustion with an equivalence ratio of 0.98 [28]. As shown by Hageman et al. [28], for this equivalence ratio, the soot produced by EEE was very similar to the one produced by ethanol and the PSDF integral order of magnitude was $10^{6}$. This value is identified as the experimental BGS and it has to be considered while comparing experimental and 3D-CFD results. The fuel-related soot PSDF integral (IPSDF) from 3D-CFD simulations is calculated, for each equivalence ratio value and for every fuel, by using a simple midpoint rule, as shown in Eq. 5. By $\mathrm{d}_{\mathrm{i}+1}$ the authors, indicates the mean diameter of the particle belonging to the section $i+1$, as well as $d_{i}$ for section i. In Eq.6 the sum of the numerical IPSDF is added to the BGS and then normalized over the background soot PSDF integral, thus using a consistent procedure with the one reported in [28]. The quantities calculated as 
in Eq.6 are depicted in Fig.6 for each fuel and compared to the experimental results reported by [28] for the EEE.

$$
\operatorname{IPSDF}\left(\Phi_{i}\right)=\sum_{i} P S D F_{i} \cdot\left(d_{i+1}-d_{i}\right) \quad \text { (5) } \operatorname{IPSDF} F^{N o r m}\left(\Phi_{i}\right)=\frac{\operatorname{IPSDF}\left(\Phi_{i}\right)+B G S}{B G S}
$$

Pure ethanol produces soot in negligible quantity for all the equivalence ratios considered in this study. As for the gasoline surrogates (TIER-2 and CHINA-6), the results exhibit a common trend in terms of sooting threshold, very similar to the experimental pattern reported by [28], with a steep increase for equivalence ratios between 1.35 and 1.4. In particular, for the oxygenated CHINA-6 surrogate, the threshold occurs for 1.4, while for the nonoxygenated TIER-2 soot formation becomes non-negligible at 1.35. This last result is of particular interest, since the 3D-CFD methodology is able to correctly predict the critical $\Phi$ sooting threshold for a non-oxygenated fuel, in agreement with the experimental evidence from [28]. Moreover, the increase of ethanol content in the gasoline results in a reduced formation of soot.

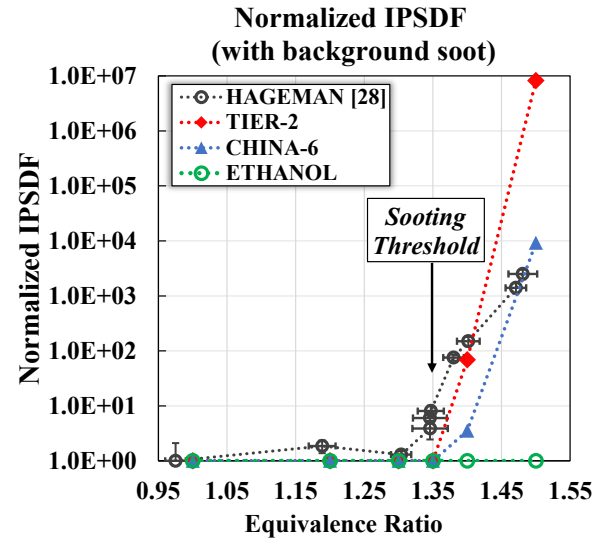

Fig. 6 Comparison of the normalized PSDF integral of this study results and [28].

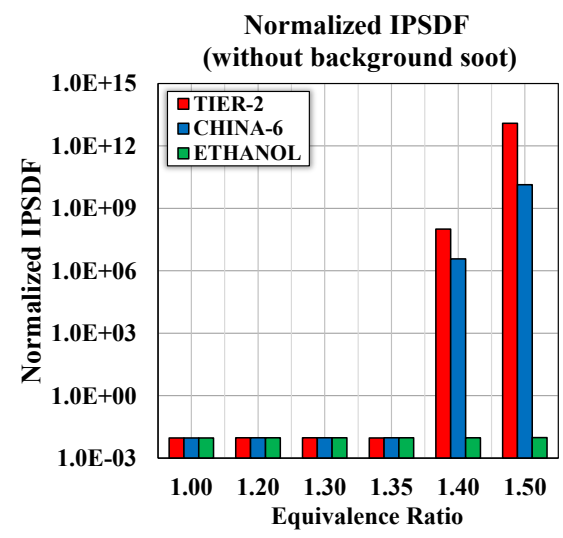

Fig. 7. Comparison of the normalized PSDF integral of this study, without considering the background soot.

As visible in Fig.6, the slope is alike to the one obtained by the experimental measurements, thus between 1.35 and 1.4 the growth rate in the soot formation is matched. For higher values of equivalence ratio, the numerical results slightly overestimate the increase of emitted particles. However, the overall experimental trend is matched for the non-oxygenated gasoline and a decrease in sooting tendency is observed as ethanol content increases. For the sake of completeness, IPSDF values without considering background soot are reported in Fig.7.

\section{Conclusions}

This study aimed to spot the sooting threshold values of the equivalence ratio for different fuels. Two gasoline fuel surrogates and pure ethanol were investigated. It was found that:

- The adopted tabulated approach accounts for the effect of fuel chemical composition on the sooting tendency. Pure ethanol exhibits a negligible soot production, as expected, while TIER-2 (ethanol 0\%vol) is more sooting than CHINA-6 (ethanol 10\%vol). The results obtained for the two gasolines provide a very positive feedback on the robustness of the proposed methodology. The competing influence of both aromatics and oxygenates content is successfully observed: CHINA-6 is less sooting than TIER-2 due to the $10 \%$ vol of ethanol content in the Chinese gasoline. 
- The sooting tendency trend is consistent for each of PN, PM and the integral of the PSDF.

- The sooting tendency hierarchy of the tested fuels is correctly simulated. Moreover, when comparing 3D-CFD results with the experimental data by [28] for the EEE (a nonoxygenated gasoline with $28 \% \mathrm{vol}$ of aromatics), the sooting threshold is spotted for the same equivalence ratio range (1.35 to 1.4$)$ and the trend obtained by simulations is consistent with the experimental one. Finally, within the equivalence ratio range $1.35 \div 1.4$, the slope for TIER-2, CHINA-6 is very similar to the experimental evidence provided for EEE.

- It is worthwhile to highlight that the aforementioned results were obtained without any case-by case tuning on the Sectional Model, thus further proving the solidity of the chosen numerical approach for soot modelling.

As a future development, it would be interesting to enable the Sectional Method to account for the soot particle size on the surface reaction mechanism to provide more precise prediction of the soot mass.

\section{References}

1. Exxon Mobil Corporation. 2017 outlook for energy: a view to 2040. Report. Irving: Exxon Mobil Corporation, (2017)

2. World Energy Council. Global transport scenarios 2050. Report. London: World Energy Council, (2011)

3. World Oil Outlook 2040. OPEC Secretariat, ISBN 978-3-9503936-4-4, (October 2017)

4. G. Kalghatgi, Eng. J., 5, p. 510-518, (2019), doi.org/10.1016/j.eng.2019.01.009

5. S. Breda, F. D'Orrico, F. Berni, A. d'Adamo, S. Fontanesi, A. Irimescu, S.S. Merola, Fuel, 243, p.104-124, (2019), doi.org/10.1016/j.fuel.2019.01.111

6. V. Pessina, A. d'Adamo, C. Iacovano, S. Fontanesi, S. Martinez, P. Lacava, SAE Technical Paper, 14, 2019-24-0094, 2019, (2019), doi.org/10.4271/2019-24-0094

7. E. Severi, A. d'Adamo, F. Berni, S. Breda, M. Lugli, E. Mattarelli, Energy Procedia, 81, p.846-855, (2015), doi.org/10.1016/j.egypro.2015.12.094

8. S. Fontanesi, G. Cicalese, A. d'Adamo, G. Cantore, Energy Procedia, 45, p.769-778, (2014), doi.org/10.1016/j.egypro.2014.01.082

9. S. Fontanesi, G. Cicalese, G. Cantore, A. d'Adamo, SAE Technical Paper, 2014-011151, (2014), doi.org/10.4271/2014-01-1151

10. S. Sparacino, F. Berni, A. d'Adamo, V. K. Krastev, A. Cavicchi, L. Postrioti, Energies 2019, p.12, 2890, (2019), doi.org/10.3390/en12152890

11. L. Postrioti, A. Cavicchi, G. Brizi, F. Berni, S. Fontanesi, SAE Technical Paper, p.17, 0148-7191, (2018), doi.org/10.4271/2018-01-0271

12. F. Berni, S. Breda, M. Lugli, G. Cantore, Energy Procedia, 81, p.826-835, (2015), doi.org/10.1016/j.egypro.2015.12.091

13. A. d'Adamo, F. Berni, S. Breda, M. Lugli, S. Fontanesi, G. Cantore, SAE Technical Paper, 2015-01-0393, (2015), doi.org/10.4271/2015-01-0393

14. A. d'Adamo, F. Berni, S. Breda, M. Lugli, S. Fontanesi, G. Cantore, SAE Technical Paper, 2015-04-14, (2015), doi.org/10.4271/2015-01-0393

15. F. Mauss, K. Netzell, C. Marchal, G. Moréac, "Particle Size Distribution Functions in Laminar and Turbulent Flames" (2019)

16. K. Netzell, H. Lehtiniemi, F. Mauss, Proc. Combust. Inst., 31, p.667-674, (2007), doi.org/10.1016/j.proci.2006.08.081. 
17. M. Del Pecchia, S. Sparacino, S. Breda, G. Cantore, AIP Conf. Proc, 2191, 020064, (2019), doi.org/10.1063/1.5138797

18. K. Netzell, Ph.D. Thesis, Lund Institute of Technology, (2006)

19. D. Aubagnac-Karkar, Mécanique des fluids, PhD Thesis, Ecole Centrale Paris, (2014)

20. C. Marchal, G. Moréac, C. Vovelle, C. Mounaïm-Rousselle, F. Mauss, "Soot Modelling in Automotive Engines," in Proc. of the European Combustion Meeting, (2009)

21. P. Vervisch-Kljakic, Ph.D. Thesis, Ecole Centrale Paris, (2011)

22. F. Bonatesta, E. Hopkins, C. Francavilla, D. Bell, A. La Rocca, "Combustion and Particulate Matter Formation in Modern GDI Engines: A Modelling Study Using CFD", In Proc. of the FISITA 2016 World Automotive Congress, Busan, Korea, 26-30 September 2016; pp. 1-13

23. D. Aubagnac-Karkar, J.Michel, O. Colin, P. Vervisch-Kljakic, N. Darabiha, Combust. Flame, 162, p.3081-3099, (2015), doi.org/10.1016/j.combustflame.2015.03.005

24. M. Del Pecchia, S. Sparacino, V. Pessina, S. Fontanesi, S. Breda, A. Irimescu, S. Di Iorio, SAE Technical Paper, p.16, 2020-01-0239, (2020), doi.org/10.4271/2020-010239 .

25. M. Del Pecchia, Ph.D Thesis, Universita' degli Studi di Modena, (2020)

26. M. Del Pecchia, S. Sparacino, S. Breda, G. Cantore, La Termotecnica, ISSN: 00403725, 07, p.48-56, (2019)

27. I. Glassman, Symposium (International) on Combustion, 22, p.295-311, (1989), doi.org/10.1016/S0082-0784(89)80036-0

28. M.D. Hageman, S. S. Sakai, D. A. Rothamer, Proc. Comb. Inst., 35, p.2949-2956, (2015), doi.org/10.1016/j.proci.2014.06.105.

29. M. Fatouraie, R. Bosch, M. Frommherz, M. Mosburger, E. Chapman, S. Li, R. McCormick, G. Fioroni, SAE Technical Paper, 2018-01-0358, (2018), doi.org/10.4271/2018-01-0358.

30. D.C. Quiros, S. Hu, S. Hu, E.S. Lee, S. Sardar, X. Wang, J.S. Olfert, H.S. Jung, Y. Zhu, T. Huai, J. Aerosol Sci., 83, p.39-54, (2015), doi.org/10.1016/j.jaerosci.2014.12.004

31. STAR-CD Version 2019.1.2, CFD/CCM User Guide, 2019 Siemens Digital Industries Software

32. M. Del Pecchia, V. Pessina, F. Berni, A. d'Adamo, S. Fontanesi, Fuel, 264, p.116741 (2020), doi.org/10.1016/j.fuel.2019.116741

33. AIP Conference Proceedings 2191, M. Del Pecchia, V. Pessina, C. Iacovano, G. Cantore, AIP Conf. Proc, 2191, 020063 (2019), doi.org/10.1063/1.5138796

34. L. Cai, A. Ramalingam, H. Minwegen, K. A. Heufer, H. Pitsch, Proc. Comb. Inst., 37, p.639-647, (2019), doi.org/10.1016/j.proci.2018.05.032

35. F. Berni, G. Cicalese, S. Fontanesi, Appl. Therm. Eng., 115, p.1045-1062, (2017), doi.org/10.1016/j.applthermaleng.2017.01.055

36. F. Berni, S. Fontanesi, G. Cicalese, A. d'Adamo, SAE Int. J. Commer. Veh. 10(2), p.547-561, (2017), doi.org/10.4271/2017-01-0569

37. G. Cicalese, F. Berni, S. Fontanesi, A. d'Adamo, E. Andreoli, SAE Technical Paper, 2017-01-2196, (2017), doi.org/10.4271/2017-01-2196

38. G. Cicalese, F. Berni, S. Fontanesi, SAE Int. J. Engines, 9(1), p.601-617, (2016), doi.org/10.4271/2016-01-0578

39. F. Berni, S. Fontanesi, Appl. Therm. Eng., 174, p. 115320, (2020), doi.org/10.1016/j.applthermaleng.2020.115320

40. F. Berni, G. Cicalese, S. Sparacino, G. Cantore, AIP Conf. Proc, 2191, 020019 (2019) doi.org/10.1063/1.5138752 
41. M. L. Botero, S. Mosbach, M. Kraft, Fuel, 126, p.8-15, (2014), doi.org/10.1016/j.fuel.2014.02.005

42. L. Pirjola, P. Karjalainen, J. Heikkilä, S. Saari, T. Tzamkiozis, L. Ntziachristos, K. Kulmala, J. Keskinen, T. Rönkkö, Environ. Sci. Technol., 49, p. 3644-3652 (2015), doi.org/10.1021/es505109u 